\title{
Cerebrotendinous Xanthomatosis
}

National Cancer Institute

\section{Source}

National Cancer Institute. Cerebrotendinous Xanthomatosis. NCI Thesaurus. Code C84628.

A rare inherited lipid-storage disorder caused by defects in the CYP27A1 gene. It is characterized by progressive neurologic dysfunction, premature atherosclerosis and development of cataracts. 